\title{
Remote sensing - a new tool in exploration geology
}

\author{
Tage Thyrsted
}

\begin{abstract}
Remote sensing techniques have been applied to mineral exploration in areas of South and East Greenland. The data consist of airborne and satellite-borne (Landsat) multispectral scanner images and geochemical and geophysical measurements interpolated into grid format and registered on the Landsat images. The main image processing methods applied include ratioing, principal component transformation/factor analysis and classification. In addition, visual and subsequent statistical analyses of lineaments were carried out on images from South Greenland. The results of the work include mapping of several hundred spectral anomalies which represent oxidation zones on the ground. The lineament analysis resulted in definition of major linear zones with increased lineament intensities; some of these zones may have geological significance. Supervised classification was carried out on an integrated data set consisting of images and geochemical/geophysical data. The training areas mainly included uranium showings, and the classified image depicts both previously known occurrences and a new area which is statistically similar to the training areas.
\end{abstract}

\section{Introduction}

In 1979 the Geological Survey of Greenland launched a project on the use of remote sensing in geology, with particular reference to exploration geology. The project was based on airborne multispectral image data from central East Greenland. Simultaneously, the Institute of Mathematical Statistics and Operations Research (IMSOR) at the Technical University of Denmark began research on multispectral images of the same area from the American satellite series 'Landsat'. With these initiatives, IMSOR and the Survey were among the first public organisations in Denmark to use remote sensing for thematic applications. After completion of the initial projects, IMSOR and the Survey decided to work together and have, so far, cooperated on two subsequent projects which have ensured continuous research on geologically applied remote sensing.

The general purpose of the projects is to investigate the applicability of remote sensing techniques in mineral exploration. In order to pursue this goal, the general progress of the projects has been, first to investigate areas with known mineralisation in an attempt to develop methods which may enhance or statistically characterise specific features connected with the mineralisation, and subsequently to apply the methods to larger areas with potential for similar mineralisation.

Remote sensing investigations involving high technology and advanced statistical computations in addition to thematic applications, call for interdisciplinary cooperation. In addition to the cooperation with IMSOR, the Survey cooperated during its first project with the French organisation 'Groupement pour le Développement de la Télédétection Aérospatiale' (GDTA), which was in charge of the acquisition and pre-processing of the airborne data and also some of the data analysis (Favard et al., 1982). All the projects described here have had financial support from research and development programmes under the Commission of the 
European Communities. The project on airborne remote sensing in East Greenland was also supported by the Danish Natural Science Research Council.

\section{Data and projects}

The remote sensing activities at the Survey have been, and are being, executed within the framework of three projects.

The first project lasted from 1979 to the end of 1982 and was based on airborne multispectral images from central East Greenland (Thyrsted, 1980). The data consisted of 7-channel visible/near-infrared images acquired by a Daedalus ${ }^{\circledR}$ scanner and 2-channel thermal infrared images acquired by a French scanner Super Cyclope SAT. The ground resolution for the images was $15 \mathrm{~m}$ and $9 \mathrm{~m}$ respectively. In total, approximately $12500 \mathrm{~km}^{2}$ were covered (Thyrsted, 1980) corresponding to an amount of raw data of 3.4 Gbyte. However, so far preprocessing has been accomplished only on data from areas of high priority (fig. 1) corresponding to about $45 \%$ of the raw data. The thermal data were of generally low quality and have been analysed only to a minor extent by the French group.

While the first project was based solely on remotely sensed data, the two subsequent projects incorporate geochemical analytical results and geophysical measurements in addition to satellite imagery.

The second project dealt with the region of South Greenland (fig. 1). The remote sensing data consisted of multispectral scanner (MSS) images of Landsat 2 and 3. The area investigated was approximately $20000 \mathrm{~km}^{2}$, for which a total of eight images were available. The ground resolution of Landsat MSS images is 79 by $79 \mathrm{~m}$, but data of the images were resampled to a 50.8 by $50.8 \mathrm{~m}$ pixel size. Other data types included geochemical analyses from approximately 2300 sites (Armour-Brown et al., 1982, 1983). The elements selected for this project include $\mathrm{U}, \mathrm{K}, \mathrm{Rb}, \mathrm{Sr}, \mathrm{Nb}, \mathrm{Ga}, \mathrm{Y}$ and $\mathrm{Fe}$ from stream sediments and $\mathrm{U}$ from stream waters. Airborne gamma-spectrometric measurements, including $\mathrm{U}, \mathrm{Th}, \mathrm{K}$, and total radiation, were also available; approximately 300000 measurements from 14000 line $\mathrm{km}$ were acquired during helicopter contour flying with an average ground clearance of $50 \mathrm{~m}$ (Armour-Brown et al., 1982). Lastly, aeromagnetic data were incorporated in the total data set; they show the total magnetic field as measured in 1968. The distance between the aeromagnetic flight lines was two kilometres while the flight height above terrain was variable, but was approximately $300 \mathrm{~m}$ above peaks. The various types of data were available either as contour maps or were electronically stored on magnetic tapes, and conversion of the data sets to a common raster format constituted a major part of the project.

In the third project, which is currently in progress, the target area is again central East Greenland, principally the region between $70^{\circ}$ and $74^{\circ} \mathrm{N}$ (fig. 1). It was hoped that Landsat 4 and 5 Thematic Mapper images, which have a ground resolution of 30 by $30 \mathrm{~m}$, would be available, but so far no acquisition by this scanner has taken place over Greenland*. As in South Greenland, other data types will also be incorporated in the new East Greenland project. The data available include aeromagnetic and gravimetric measurements on a regional scale and geochemical analyses from local areas.

\footnotetext{
${ }^{*}$ Images from summer 1985 are now available.
} 
COVERAGE :

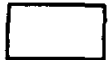

Landsat MSS

\section{1-- - Airborne}

-. .1 multispectral

0 $150 \mathrm{~km}$
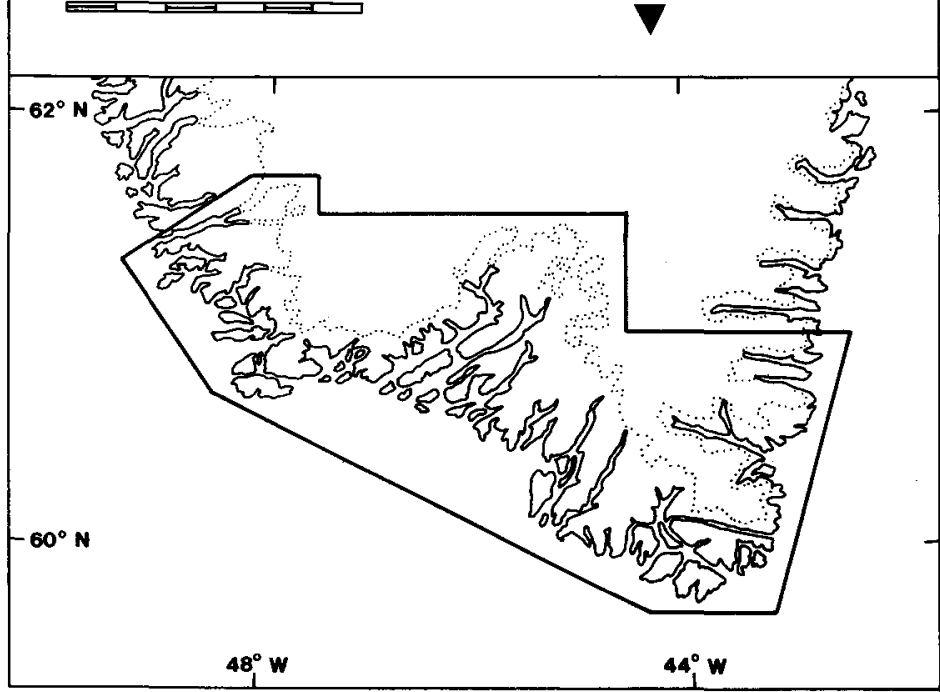

$48^{\circ} w$

Fig. 1. Maps showing the analysed areas and the coverage of the satellite and airborne data. Airborne data were acquired from a larger area than shown here (see Thyrsted, 1980), but only data from the areas indicated have been processed. 


\section{Definitions and methods}

The definition of remote sensing may apply at different levels. In a broad sense, remote sensing literally means the collection of information about an object without being in physical contact with it (Sabins, 1978). This encompasses not only modern multispectral and/or digital data acquisition but also conventional aerial photography and most geophysical methods. In order not to trespass into the area of e.g. the geophysicists, a more narrow definition of remote sensing restricts the method to that employing electromagnetic energy as the means of detecting and measuring target characteristics (Sabins, 1978).

An essential part of remote sensing investigation is image analysis. By an image is here meant a two-dimensional gridded arrangement of data which may represent any kind of measurement. Each 'mesh' in the grid of such an image is called a pixel (from picture element). An image may consist of one or more channels or bands. The data may be stored electronically as digital values, e.g. on magnetic tapes or discs, or as pictorial representations where the digital values are depicted as grey tones or colours. The two-fold aspect of the storage medium is again reflected in a two-fold aspect of the analysis method. Visual analysis is based on pictorial images and makes use of the ability of the human mind to qualitatively evaluate spatial patterns in a scene and to make subjective judgments on the basis of selective scene elements (see e.g. Lillesand \& Kiefer, 1979), while numerical analysis is based on digital values. The advantage of numerical analysis is its ability to enhance spectral characteristics and to handle, simultaneously, numerous image bands, whereas it is still inferior to visual analysis in the evaluation of spatial patterns. Thus the two techniques are complementary and the combination of the two approaches is one of the innovations of image analysis.

Three main methods have been used in the investigations and are described below, followed by a short review of other methods applied. The contribution of remote sensing in geoscience can roughly be ascribed to two aspects, namely the multispectral information and, for satellite images, the synoptic view of regional areas. These aspects form the basis for the first two methods described.

The multispectral information is the basis for recognition of colour anomalies. These may be enhanced by methods of ratioing or by factor analysis. During ratioing, the quotient between the digital values of corresponding pixels in two image bands is calculated. On the resulting image, features with characteristic spectral responses in the two bands in question will be enhanced. During factor analysis, correlated image data are 'de-correlated'. By correlation is meant that features which in one band appear e.g. bright relative to the surroundings, will also appear bright in other bands; for instance snow in any band within the visible part of the spectrum will always appear as bright areas relative to soil and rocks. It is beyond the scope of this paper to explain the statistical calculations behind factor analysis, but in summary it can be stated that features with anomalous spectral characteristics may become apparent on images resulting from factor analysis. The two methods for enhancement of colour anomalies have been used in the Greenland projects in the search for oxidation zones.

The synoptic view of regional areas, provided by satellite imagery, has been used for lineament analysis. In contrast to the above-mentioned ratioing and factor analysis techniques, where numerical computations precede a visual survey of enhanced colour anomalies, lineament analysis began with visual mapping of linear features as seen on photographic prints of Landsat images. This mapping was followed by digitisation and statistical analysis of the 
lineaments. On the basis of this analysis, histograms showing the relative frequency of lineaments of a given direction and maps showing the geographical density of lineaments of a given direction could be produced. The density maps formed the basis for locating major zones of high lineament densities which may be interpreted as zones of crustal weakness.

A third major method applied in the investigations is classification. During classification pixels are assigned to various categories on the basis of similarities of digital values. The categories can be defined by training areas (supervised classification) which are known to represent specific types of features (e.g. water, land or snow/ice) or by the statistical properties of the image data (unsupervised classification). Clustering of the data may be a typical statistical property. In the investigations reported here, supervised classification was carried out on the airborne remote sensing data and on integrated data sets, including remotely sensed imagery, geochemical analytical results, and aeromagnetic and radiometric measurements.

In addition to the methods described above, the work included presentation of images using intensity-hue-saturation (IHS) colour coordinates and development of methods for automatic lineament analysis. The IHS presentation may be particularly useful where the resolutions between the various image bands are very different, which might arise when one integrates e.g. Landsat images with aeromagnetic measurements. The automatic lineament mapping, which is in its initial phase, includes filtering to enhance high-frequency features.

\section{Results}

The description of the analyses and interpretations which follows is divided on the basis of the methods applied during the investigations rather than on the basis of the single projects. This is because some of the methods are common to the investigations in South and East Greenland and could, with minor adjustments, be applied in both areas. This applicability in various areas indicates that some of the methods developed may be at least semi-operational and may find application in other parts of Greenland or elsewhere.

\section{Mapping of oxidation zones}

The best results from the investigations were obtained on enhancement of oxidation zones. Part of the airborne data covered a region in East Greenland with Tertiary alkaline intrusions, including a molybdenite-mineralised porphyritic granite. A pronounced oxidation zone is associated with this mineralisation giving the granite and the surrounding host rocks a rusty colour. Manipulation of the multispectral airborne image data from this granite area showed that it was possible to considerably enhance the oxidation zone by use of ratioing techniques (fig. 2). The most appropriate image channels for the ratioing appeared to be channel $4(0.50-0.55 \mu \mathrm{m})$ divided by channel $5(0.55-0.60 \mu \mathrm{m})$, channel $6(0.60-0.65 \mu \mathrm{m})$ and channel $7(0.65-0.70 \mu \mathrm{m})$. Once the method was established it was applied to the whole region surrounding the Tertiary intrusions and resulted in enhancement and localisation of several hundred oxidation zones (Thyrsted \& Friedman, 1982).

The investigations undertaken by IMSOR on Landsat imagery from the same area resulted in similar enhancement of oxidation zones (Conradsen et al., 1982). The methods they 

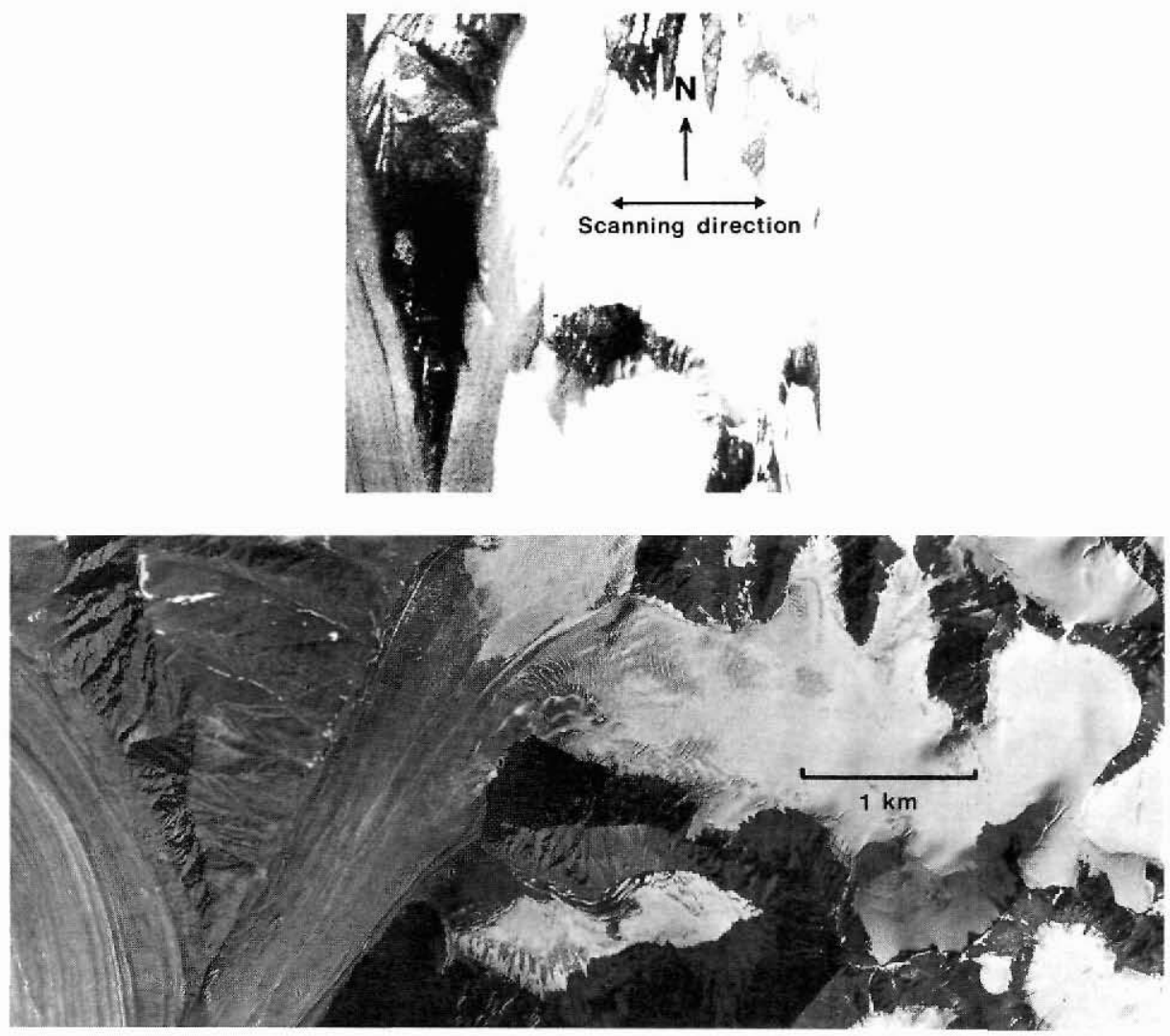

Fig. 2. Airborne, digital image of Malmbjerg (above). The image is created by the quotient between a band in the green and a band in the red part of the spectrum. The oxidation zone is seen as a dark zone (central left). The side length of the picture is approximately $7 \mathrm{~km}$. For comparison, a conventional aerial photograph of the same area is reproduced below. Note the difference in distortion in the two pictures, in particular the shortening in the scanning direction of the digital image.

used included ratioing, factor analysis and classification. The latter was based on a total data set consisting of the original images, and ratio and factor plots, each of which enhances the oxidation zones. This technique could, with minor adjustment of the stretching parameters, be applied on Landsat images from South Greenland. It must be emphasised, however, that the adjustments must be based on data from at least one known oxidation zone in the new area. The survey of the South Greenland region resulted in delineation of several oxidation zones, particularly in the area around the Igaliko intrusive complex (A on fig. 3, Emeleus \& Upton. 1976). It should be noted that the method is applicable only to areas devoid of vegetation. As the area around the Igaliko complex is of high altitude with sparse vegetation any oxidation zones are more likely to be detected than at other places in South Greenland which have a fairly continuous vegetation cover.

Ground control field work in both East and South Greenland has shown an almost $100 \%$ correlation between colour anomalies and the presence of oxidation zones. Despite all mod- 
ern exploration and prospecting techniques, oxidation zones are still important target areas in exploration. Hence mapping of such zones, which can be accomplished during early stages of exploration, may be very valuable, particularly in areas which are unexplored or difficult of access.

\section{Lineaments}

A lineament analysis was carried out during the South Greenland project (Conradsen et al., 1984). The analysis was executed on the basis of photographic prints of Landsat images at a scale of 1:1 000000 . In total 924 lineaments were mapped and digitised. A statistical treatment of the digitised lineaments, which was developed from that of Sawatzky \& Raines (1981), showed that three directions $\left(\mathrm{N} 75^{\circ} \mathrm{E}, \mathrm{N} 55^{\circ} \mathrm{E}\right.$, and $\left.\mathrm{N} 75^{\circ} \mathrm{W}\right)$ were very common and may have geological significance. For each of the three directions a lineament density map was produced on the basis of which zones of high lineament concentrations could be interpreted (fig. 3). Examples of the geological significance of the lineament zones are given below.

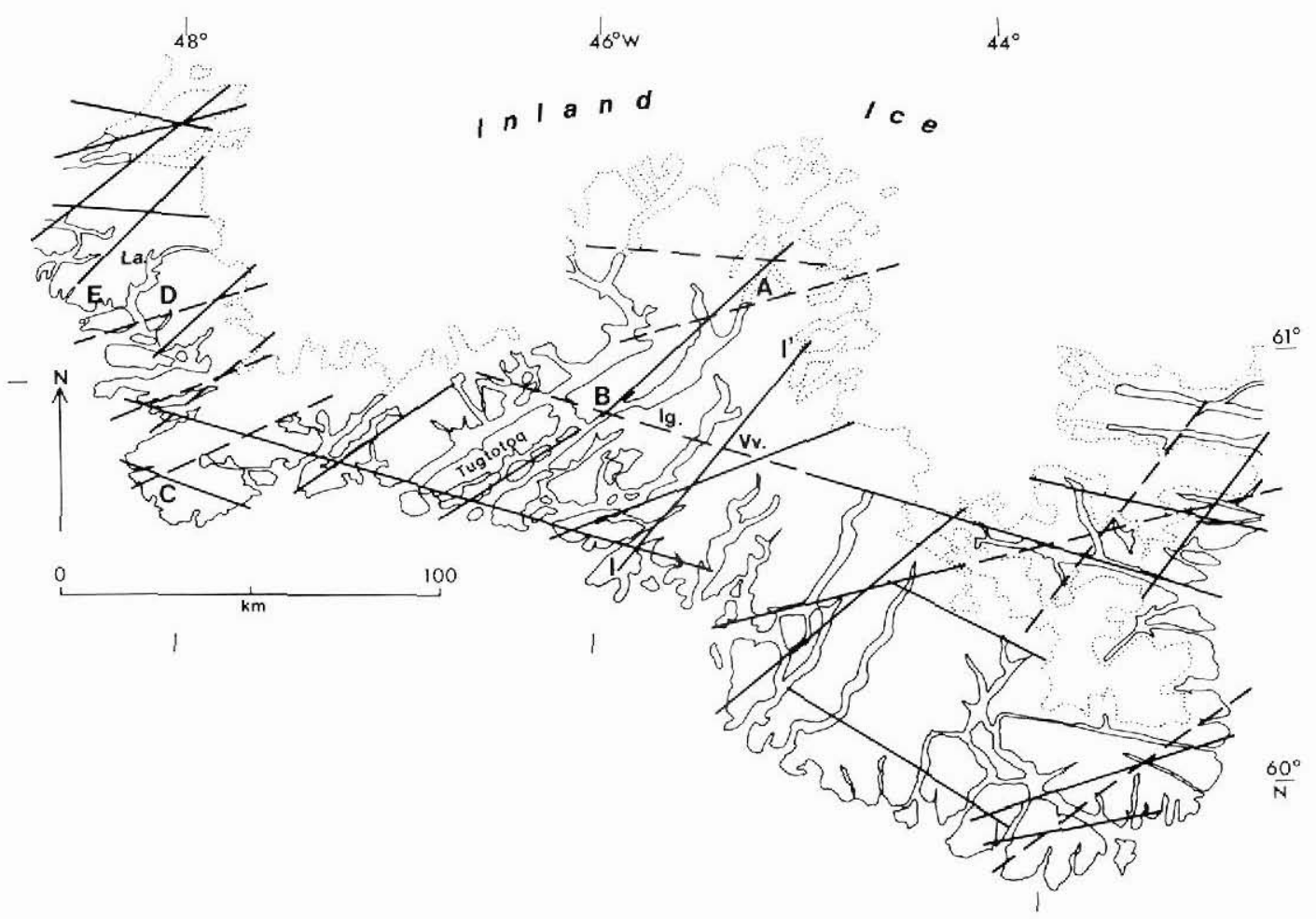

Fig. 3. Map of South Greenland showing zones of high lineament concentrations as interpreted from density maps for lineament directions $\mathrm{N} 75^{\circ} \mathrm{E}, \mathrm{N} 55^{\circ} \mathrm{E}$ and $\mathrm{N} 75^{\circ} \mathrm{W}$. The width of the zones may be broader than the actual lines shown here. Gardar intrusive complexes: A - Igaliko. B - llímaussaq. C Nunarssuit, D - Grønnedal-Ika, E - Kûngnât. Ig.: Igaliko peninsula; Vv.: Vatnahverfi; La.: Laksenæes fault. 
Some of the major Gardar intrusions (Emeleus \& Upton, 1976), Igaliko, Ilímaussaq and Nunarssuit (fig. 3, A, B and C, respectively) are situated at the intersections between two or more lineaments, suggesting a possible control by the lineaments on the sites of these intrusions. The Grønnedal-Ika and Kûngnât intrusions (fig. 3, D and E) do not seem to be associated with any lineament intersections, although the Grønnedal-Ika intrusion does lie close to an ENE-WSW lineament.

The lineament marked I-I' on fig. 3 coincides with a notable geochemical boundary (Armour-Brown et al., 1983) where elements such as niobium and uranium show distinctly higher concentrations on the north-west side of the lineament than on the south-east side. The lineament is also believed to delimit the south-east boundary of a major NE-SW trending graben system which was active during the Gardar period.

Armour-Brown et al. (1984) and Nyegaard et al. (in press) report on uranium occurrences in association with fractures and faults within the 'Julianehåb granite' (Allaart, 1976). A comparison of these uranium occurrences with the lineament zones on fig. 3 shows that some of the occurrences are, at least spatially, associated with some of the lineaments, particularly on the Igaliko peninsula and in the Vatnahverfi area. Other uranium occurrences cannot be related to any of the lineaments.

In an evaluation of the contribution of this type of lineament analysis to the geological knowledge of the area it is necessary to determine, on the one hand, where new information has been obtained and, on the other, where existing knowledge from other sources has not been revealed by the analysis. Thus, the three main lineament directions, $\mathrm{N} 75^{\circ} \mathrm{E}, \mathrm{N} 55^{\circ} \mathrm{E}$, and $\mathrm{N} 75^{\circ} \mathrm{W}$, are the same as those reported in the geological literature to have major geological significance (e.g. Armour-Brown et al., 1984; Berthelsen \& Henriksen, 1975; Nyegaard et al., in press; Stephenson, 1976). The lineament zones in the migmatite zone (Allaart, 1976) are new information, the geological significance of which has still to be assessed by future investigation.

Among the linear features shown on existing geological maps (e.g. Allaart, 1975), but not appearing on fig. 3, are the ESE-WNW striking faults at Laksenæs (Henriksen, 1960) and on central Tugtutôq. Two remarks can be made in this connection. Firstly, the lineaments on fig. 3 represent zones where linear features, trending parallel with the zones, are particularly common, but this does not mean that linear features of the direction in question are not present in areas between the zones; in fact, the two faults mentioned above have been mapped from the satellite images. Secondly, the visual mapping of the linear features could be improved in several ways. For example, the photographic prints which vere used for the mapping were based on raw data and were not specially treated for lineament determination, and only one image scale (1:1000 000) was used; it is envisaged that by applying different scales, ranging from 1:2 500000 to $1: 250000$, or even up to the scale of aerial photographs, many more lineaments could be distinguished simply because what may appear as a lineament at one scale may be completely invisible at another.

The lineament analysis carried out in South Greenland indicates the potential of the method in exploration geology, but it is recognised that a more careful and comprehensive analysis is necessary in order to obtain full appreciation of the method. 


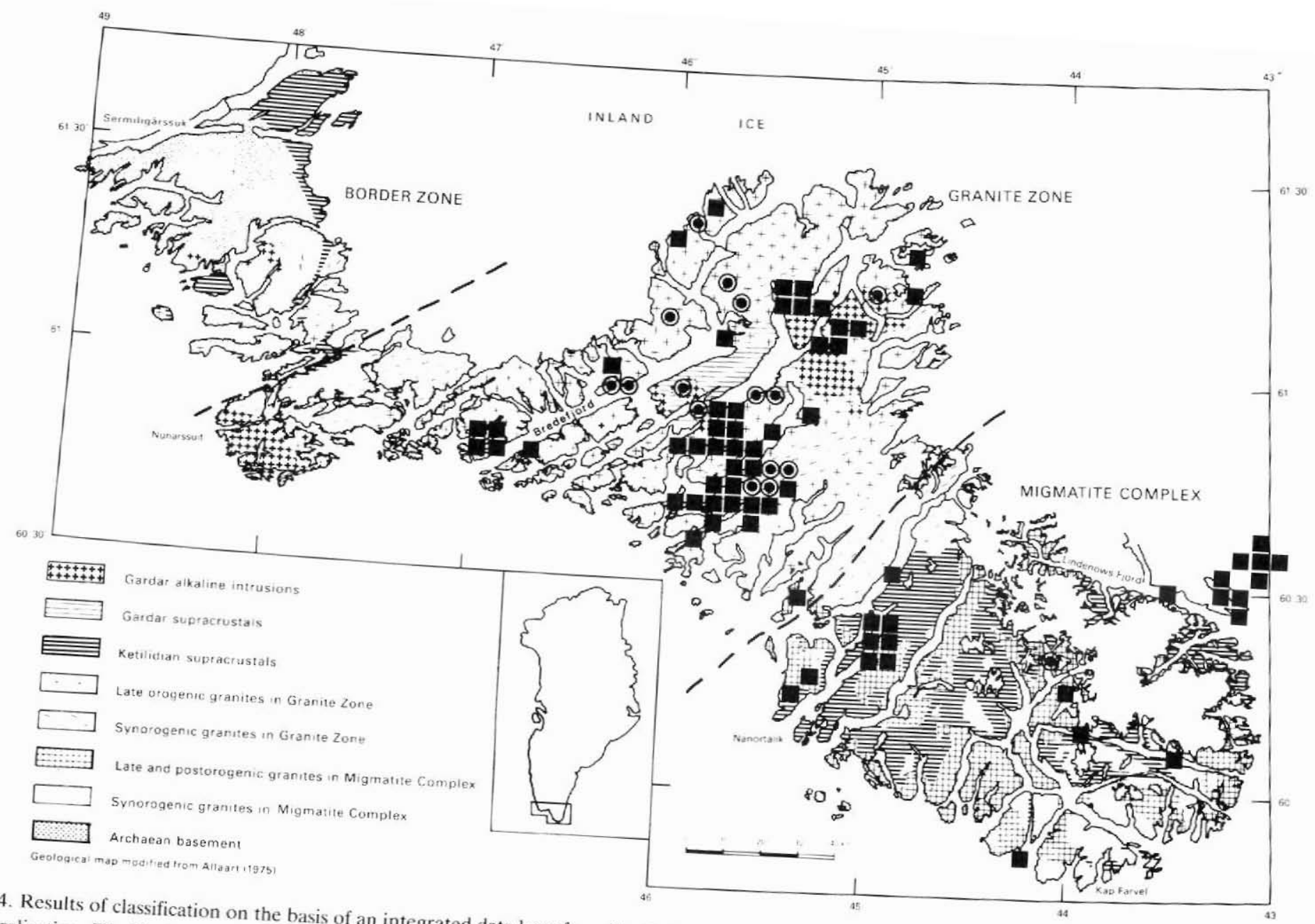

Fig. 4. Results of classification on the basis of an integrated data base from mineralisation. exploration. 


\section{Classification}

Classification was carried out at several stages of the project, and two attempts, aimed directly at exploration methods, will be mentioned here.

The first was based on airborne multispectral data from East Greenland. The purpose was to make an automatic classification of the various rock formations which here consist of flatlying, easily distinguishable sedimentary rocks, some of which contain strata-bound base metal mineralisation. However, the procedure of classification of rock types proved very difficult and only poor results were obtained. While it was possible locally to make a partly correct classification of the rock types, the method could not be extended to larger areas and further work was not carried out.

The other classification was carried out on the compiled data base from South Greenland. Part of the South Greenland project was to incorporate the different types of data sets from the area into a data base on a common raster image format. The data base comprised the original Landsat images, the manipulated images such as ratio and factor plots, lineament densities, and the geophysical and geochemical variables. In total about 40 variables were available which meant that the data base could be considered as an image with 40 channels on which classification could take place. In order to reduce the amount of data, a degradation of the image from a pixel size of $50.8 \mathrm{~m}$ to a $5 \mathrm{~km}$ pixel size was made (Conradsen et al., 1984).

The classification made was supervised on the basis of training sets, including mineralised areas (mainly uranium showings) and areas which our present knowledge suggests are barren. The statistics of the two types of training sets grouped nicely into two well-defined, separate clusters, indicating that the training sets were significantly different, statistically, and that the classification could be expected to be meaningful.

The results of the classification are shown on fig. 4 where the circled dots indicate the mineralised training areas and the black squares indicate the 5 by $5 \mathrm{~km}$ pixels which were attributed to the mineralised class by the classification. From the statistics it is known that the uranium values contribute most to the total variation. This is reflected in the classified image (fig. 4) where the black squares to a large extent coincide with known uranium occurrences. This demonstrates that the classification can be considered as a success and is geologically meaningful. In addition to the depiction of known occurrences, the classification result points to a new potential exploration area at the mouth of Bredefjord. In the extreme east, the classification of several squares north of Lindenows Fjord may be fortuitous as the data set is not complete in that area.

\section{Conclusions}

The remote sensing technique has proved its value within certain aspects of exploration geology. The multispectral information, which is the basis for the ratio and factor analysis methods, can be used for enhancement and mapping of oxidation zones which are important features for exploration geologists. The large areas covered by satellite images are appropriate for lineament analysis, partly because the images are acquired almost instantaneously and hence form a uniform basis for the analysis, which is important because of the subsequent statistical treatment, and partly because the synoptic view may reveal new and unknown relationships between structures. The lineament analysis method described here is of 
great value because it is fairly straightforward and can, at the present stage, be considered as an operational technique applicable to other areas in and outside Greenland.

Classification of rocks, based on the airborne, remotely sensed data alone, proved very difficult and operational methods for this technique will probably not be developed in the near future. On the other hand, it is envisaged that the results of multivariate analysis of several data sets, including classification, will prove to be a potentially forceful tool in future investigations, because the many data sets can be easily handled by modern computer techniques. In South Greenland at least one new area of potential exploration value has been defined by classification of multivariate data sets. However, the methods of analysis should be carefully selected in order to give meaningful and useful results.

Owing to its remoteness and difficulty of access, Greenland is a country where remote sensing methods can be of great value for future investigations. However, as a paradox, poor logistic facilities in much of the country make it difficult to control in the field the analytical results and interpretations. Despite this drawback, it is significant that the Survey has succeeded in introducing the remote sensing technique at a relatively early stage and has been able to influence the development of thematic application methods.

Acknowledgements. The remote sensing projects are partly financed by the Commission of the European Communities under its programmes on Research and Development of Primary Raw Materials (the East Greenland projects) and on Research and Development for the Atomic Energy Community in the field of uranium exploration and extraction (the South Greenland project). In addition, the airborne project in East Greenland was supported by the Danish Natural Science Research Council. Nordisk Mineselskab A/S, Copenhagen, gave logistic support during field work and free access to its geological files, and Kryolitselskabet $\emptyset$ resund A/S, Copenhagen, placed its aeromagnetic data from South Greenland at the author's disposal. Niels Henriksen is thanked for valuable discussions and suggestions throughout the duration of the projects, as is Art Friedman for the pleasant and patient way in which he introduced me to the mysteries of computers and image analysis programmes. My co-workers at IMSOR, Knut Conradsen, Bjarne K. Nielsen and Gert Nilsson, are thanked for keeping me busy through their never-ceasing production of manipulated images. Niels Henriksen and A. K. Higgins critically read the manuscript.

\section{References}

Allaart, J. H. 1975: Geological map of Greenland 1:500 000, Sheet 1, Sydgrønland. Copenhagen: Geol. Surv. Greenland.

Allaart, J. H. 1976: Ketilidian mobile belt in South Greenland. In Escher, A. \& Watt, W. S. (edit.) Geology of Greenland, 121-151. Copenhagen: Geol. Surv. Greenland.

Armour-Brown, A., Tukiainen, T. \& Wallin, B. 1982: The South Greenland uranium exploration programme. Final report. 142 pp. Copenhagen: Geol. Surv. Greenland.

Armour-Brown, A., Steenfelt, A. \& Kunzendorf, H. 1983: Uranium districts defined by reconnaissance geochemistry in South Greenland. J. Geochem. Explor. 19, 127-145.

Armour-Brown, A., Tukiainen, T., Nyegaard, P. \& Wallin, B. 1984: The South Greenland regional uranium exploration programme. Final report of progress 1980-1983. 140 pp. Copenhagen: Geol. Surv. Greenland.

Berthelsen, A. \& Henriksen, N. 1975: Descriptive text to Geological Map of Greenland 1:100 000, Ivigtut, 61 V 1 Syd. 169 pp. Copenhagen: Geol. Surv. Greenland (also Meddr Grønland 186, 1). 
Conradsen, K., Gunulf, J., Harpøth, O. \& Nilsson, G. 1982: The application of remote sensing in mineral exploration. EEC final report. 175 pp. Lyngby: IMSOR, Techn. Univ. Denmark.

Conradsen, K., Nielsen, B. K., Nilsson, G. \& Thyrsted, T. 1984: Application of remote sensing in uranium exploration in South Greenland. EEC final report. 164 pp. Lyngby: IMSOR, Techn. Univ. Denmark (also Research Report 22/1984. IMSOR, Techn. Univ. Denmark).

Emeleus, C. H. \& Upton, B. G. J. 1976: The Gardar period in Southern Greenland. In Escher, A. \& Watt, W. S. (edit.) Geology of Greenland, 153-181. Copenhagen: Geol. Surv. Greenland.

Favard, J. C., Scanvic, J. Y., Friedman, A. L. \& Thyrsted, T. 1982: Le Groenland oriental, un example d'application du traitement interactif des données de télédétection à la cartographie géologique et à la recherche minière. Chron. Rech. Min. 464, 27-44.

Henriksen, N. 1960: Structural analysis of a fault in south-west Greenland. Bull. Grønlands geol. Unders. 26 (also Meddr Grønland 162, 9), 40 pp.

Lillesand, T. M. \& Kiefer, R. W. 1979: Remote sensing and image interpretation. 612 pp. New York: J. Wiley \& Sons.

Nyegaard, P., Armour-Brown, A. \& Steenfelt, A. in press: Vein type uranium mineral occurrence in South Greenland. In Fuchs, H. D. (edit.) Vein type uranium deposits. Vienna: International Atomic Energy Agency.

Sabins, Jr., F. F. 1978: Remote sensing. Principles and interpretation. 426 pp. San Francisco: W. H. Freeman \& Co.

Sawatzky, D. L. \& Raines, G. L. 1981: Geological uses of linear feature maps from small scale images. In O'Leary, D. W. \& Earle, J. L. (edit.) Proceedings of the third international conference on basement-tectonics, Durango, Colorado, 91-100. Denver: Basement Tectonics Commitee, Inc.

Stephenson, D. 1976: A simple-shear model for the ductile deformation of high-level intrusions in South Greenland. $J$ geol. Soc. London 132, 307-318.

Thyrsted, T. 1980: Airborne remote sensing in East Greenland. Rapp. Grønlands geol. Unders. 100, 101-105.

Thyrsted, T. \& Friedman, A. L. 1982: Airborne remote sensing in East Greenland. Final report. 130 pp. Copenhagen: Geol. Surv. Greenland.

Geological Survey of Greenland Oster Voldgade 10, DK-1350 Copenhagen $K$, Denmark. 